\title{
Challenges and prospects of population genetic studies in terns (Charadriiformes, Aves)
}

\author{
Patrícia J. Faria $^{1,2}$, Erika Baus ${ }^{2}$, João S. Morgante ${ }^{1}$ and Michael W. Bruford ${ }^{2}$ \\ ${ }^{1}$ Departamento de Genética e Biologia Evolutiva, Instituto de Biociências, Universidade de São Paulo, \\ SP, Brasil. \\ ${ }^{2}$ Biodiversity and Ecological Processes Group, Cardiff University, Cardiff, UK.
}

\begin{abstract}
Little information is available about the population structure of communally nesting terns (Sternidae) and skimmers (Rynchopidae) throughout the world. In order to fill this gap, a survey of molecular markers was carried out for six species of terns (Anous stolidus, Sterna hirundinacea, S. fuscata, S. superciliaris, Thalasseus maximus and Phaetusa simplex) and one species of skimmer (Rynchops niger). First, we describe the results of the construction of genomic DNA libraries and document problems encountered during this procedure. Secondly, we tested the cross-amplification of 18 microsatellite loci previously described for related species (the number of polymorphic loci ranged from three to seven). Thirdly, we tested the usefulness of mtDNA (control region, ND2, Cytochrome $b$ and ATPase 6/8) for phylogeographic studies in this group of birds. The occurrence of nuclear copies of the mitochondrial control region is reported. Nucleotide divergence in the mtDNA genes analyzed ranged from 0.0 to 0.006 . Despite the difficulties associated with the selection of variable markers in this group of seabirds, we were able to select polymorphic markers for each species tested and we anticipate these results will help the development of genetic studies concerning important biological questions in terns.
\end{abstract}

Key words: molecular markers, microsatellites, mitochondrial DNA, terns.

Received: October 20, 2006; Accepted: March 8, 2007.

\section{Introduction}

Terns (Sternidae, Charadriiformes) are migratory seabirds widely dispersed throughout the world and include several threatened species (Gochfeld and Burger, 1996). Despite this, there is not enough information about many species to enable effective conservation measures to be taken and several important biological questions regarding their dispersal behavior are not yet understood.

Molecular markers have been useful for addressing many questions in conservation and population biology. From 44 extant species of terns, only three have been genetically studied at the population level (S. fuscata, S. dougalli and S. albifrons) (Avise et al., 2000; Peck and Congdon, 2004; Szczys et al., 2005; Whittier et al., 2006). To carry out such genetic studies, it is important to obtain markers that provide suitable levels of variation for the scope of the proposed questions, which are so far unknown for terns.

Two main types of molecular markers can be used: general (e.g. RAPDs, ISSR and AFLP) or locus-specific

Send correspondence to Patrícia de Jesus Faria. Present address: Biodiversity and Ecological Processes Group School of Biosciences, Cardiff University, CF10 3TL Cardiff, United Kingdom. E-mail: patfariabio@yahoo.com.br / fariap@cf.ac.uk. markers. Among the locus-specific markers, microsatellites have become widely applied for several types of study, due to their advantages over other markers, such as the relative ease in obtaining markers, their use with non-invasive samples, their high level of variation and the possibility of cross amplification (Bruford et al., 1996; Beaumont and Bruford, 1999).

However, while in many organisms the first and apparently simple step of isolating variable microsatellites is an easy task, in others it has proved to be problematic and can be both time-consuming and expensive (Beaumont and Bruford, 1999). It is known that the abundance of microsatellites across the taxa varies by orders of magnitude (Nève and Meglécz, 2000), and in some groups, such as birds, their frequency is relatively low (Primmer et al., 1997; Neff and Gross, 2001). In addition, major difficulties in the isolation of these markers have been reported for groups such as leptidoptera (Saccheri and Bruford, 1993), birds (Beaumont and Bruford, 1999) and some plants (Squirrell et al., 2003).

Mitochondrial DNA is also extensively used in evolutionary studies because of its unique characteristics such as predominantly maternal inheritance, lack of recombination 
and high evolutionary rate. Conserved primers can be used to amplify DNA in divergent taxa (Kocher et al., 1989) and this enhances the application of mitochondrial DNA. Nevertheless, a high number of studies reported the existence and amplification of nuclear copies of mitochondrial DNA in many organisms (cats: Lopez et al., 1994; gorillas: Thalmann et al., 2005; humans: Mourier et al., 2001; Tourmen et al., 2002 and other eukariotes: Richly and Leister, 2004), including several species of birds (Quinn, 1992; Arctander, 1995; Kidd and Friesen, 1998; Sorenson and Quinn, 1998). When undetected, these nuclear sequences, which are known as nuclear mitochondrial translocated sequences (Numts) (e.g. Zhang and Hewitt, 1996; Sorenson and Quinn, 1998; Richly and Leister, 2004), can lead to misinterpretations of phylogenetic and population genetic data.

It is relatively uncommon to find reports documenting difficulties related to the use and development of molecular markers in some groups. In this paper, we describe problems encountered while conducting population genetic studies in terns that breed in Brazil. First, we describe issues associated with isolating microsatellite loci; second, the occurrence of nuclear copies of mtDNA involving the control region and third, low variation of the few molecular markers available. In order to select and test markers, six species of terns (Anous stolidus, Sterna hirundinacea, $S$. fuscata, S. superciliaris, Thalasseus maximus and Phaetusa simplex) and one species of black-skimmer (Rynchops niger) were evaluated. Our aims were to select polymorphic and useful molecular markers for conducting population genetic studies in different species of terns and skimmers and also to report our results to researchers attempting to select informative markers in 'recalcitrant' species. By reporting this information we hope to improve general understanding of the dynamics of these markers in different groups.

\section{Material and Methods}

\section{Samples and DNA extraction}

The blood samples used in this study were taken during the field work of 2001 to 2004 and are part of a broader study involving population genetics of different species of tern that breed in Brazil. Chicks and adults were captured using hand nets and mist nets at 16 different locations in Brazil. During this survey, 1200 blood samples $(200 \mu \mathrm{L}$ of blood) from 11 species were taken from the brachial vein. In laboratory, these samples were kept in absolute ethanol at $4{ }^{\circ} \mathrm{C}$ and the genomic DNA was isolated using standard phenol-chloroform extraction followed by ethanol precipitation (Sambrook et al., 1989).

\section{Microsatellites}

Enriched and non-enriched genomic libraries were constructed for two species (Sterna hirundinacea and Rynchops niger), using a well-established protocol de- scribed by Hammond et al. (1998), e.g. Williams et al. (2002), Harper et al. (2006). DNA was digested with MboI and selected fragments (300-1000 bp) were isolated from a $2.0 \%$ agarose gel by electroelution into dialysis tubing and purified using Centricon tubes (Amicon). For the enriched library, fragments were enriched for CA and GA repeats using biotin-labelled probes (Hammond et al., 1998). The fragments of both enriched and non-enriched libraries were ligated into a pUC18 vector and the ligation products were cloned into Invitrogen Topo-one shot competent cells (Top10). Colonies were screened following the PCR-based method of Lunt et al. (1999). Positive clones were sequenced directly from the PCR products using Big Dye Terminator Sequencing kit (version 2.0, ABI) following the manufacturer's instructions. Primers for those sequences containing microsatellites were designed using Primer 3 (http://www.basic.nwu.edu/biotools/Primer3. $\mathrm{html}$ ) and DSGene 1.0 (Accelrys Inc).

The microsatellites isolated from the genomic libraries, together with eighteen additional microsatellite loci previously described in the literature for other species including the Red-billed Gull (RBG 13, RBG18, RBG20, RBG27, RBG28, RBG29 and RBG39; Given et al., 2002), the Black-legged Kittiwake (K6, K16, K31, K32, K56, K67 and K71; Tirard et al., 2002) and the Roseate Tern (Sdaat20, Sdaat27, Sdaat46 and Scaac20; Szczys et al., 2005), were tested in at least 14 specimens of each studied species.

Amplifications were performed in a Perkin Elmer thermocycler (9700) using a fluorescent primer (TET, HEX or 6-FAM) and the Qiagen Multiplex PCR Kit (Qiagen) according to the manufacturers instructions. PCR products were visualized and sized on an automated DNA sequencer (ABI PRISM 377) using TAMRA-350 size standard (ABI) and GENESCAN version 2.0 (ABI). The software GENOTYPER 1.1 was also used to identify alleles and genotypes.

\section{Mitochondrial DNA}

In order to select mitochondrial regions suitable for genetic studies on terns, eighteen previously described (and one newly designed) primer pairs were tested. The first (5') domain of control region was amplified using the primers CH16746L (ACCCCAAGGACTACGGCTTGAA) (Wenink et al., 1994) and T5437R (GGGTTGCTGATTTCAC GTGA) (Avise et al., 2000). The second domain was amplified with L438 (TCACGTGAAATCAGCAAC) (Wenink et al., 1993) and HDL 13 (GTATTCCTGAGGGC CAAACT), and the third (3') domain was amplified using H1248 (CATCTTCAGTGCCATGCTTT) and L699 (ATA AACCCCTCCAGTGCACC) (Crochet and Desmarais, 2000). In order to avoid nuclear copies, long PCRs were also performed and the combinations of the following primers were tested: L14993 (CCATCCAACATCTCAGC YTGAAAYTT), H 16065 (GGAGTCTTCAGTTTTTGG TTTACAAGAC), L15569 (ATCCCATTCCACCCCTAC 
TACTC), H1816 (GCACCGCCAAGTCCTTAGAGTT), UUL 16076 (AAAACATTGGTCTTGTAAACC) (Helbig and Seibold, 1999), H519 (GGCCCTGACATAGGAAC CAGAGG) and H419 (GGGTTGCTGATTTCACGTGA) (Liebers et al., 2001). Figure 1 shows the flanking position of these primers in the control region.

A portion of the cytochrome $b$ gene ( $320 \mathrm{bp}$ ) was amplified using L15008 (AACTTCGGATCTCTACTAGG) and H15326 (GAATAAGTTGGTGATGACTG) (Desjardin and Morais, 1990). Partial sequences of the ND2 gene $(500 \mathrm{bp}$ ) were obtained using the primers MetL (AAGCT ATCGGGCCCATACCCG) and H5766 (GATGAGAAG GCTAGGATTTTKCG) (Sorenson et al., 1999), while for the amplification of a portion of the ATPase 6/8, Lys L (CAGCACTAGCCTTTTAAGCT) (Sorenson et al., 1999), and ATP6 intH (TGGGATTAGATGTTTTCTTG) (designed for this study) were used.

Amplifications were carried out in a MJ Research thermocycler (PTC-100 and PTC-200) using: an initial denaturation step of $95^{\circ} \mathrm{C}$, followed by 35 cycles of $95^{\circ} \mathrm{C}$ for $30 \mathrm{~s}, 55-60{ }^{\circ} \mathrm{C}$ for $30 \mathrm{~s}$ and $72{ }^{\circ} \mathrm{C}$ for $30 \mathrm{~s}$, with a final elongation step of $72{ }^{\circ} \mathrm{C}$ for $10 \mathrm{~min}$. Long PCRs were carried out using the TripleMaster System (Eppendorf) following the manufacturer's instructions.

PCR products were purified using shrimp alkaline phosphatase/exonuclease I enzymes (Amersham Biosciences) and sequenced using the Big Dye Terminator Sequencing kit (version 3.1, ABI) following the manufacturer's instructions. The products were loaded in an automated sequencer (ABI 3100 and 3700). Sequences were aligned manually, corrected using the program Sequence Navigator (version 1.0, Applied Biosystems) and aligned with sequences in GenBank to check if they matched mtDNA sequences already available.

\section{Results and Discussion}

\section{Microsatellites} 1162 recombinant clones and from this total only 451 positives (white colonies) were recovered: 288 clones for $S$.
Isolation: the enriched libraries yielded a total of

hirundinacea and 163 for $R$. niger. The positives were screened for the presence of microsatellites, however due to the low number of clones identified as potentially containing microsatellites (less than 5\%), all clones with inserts larger than 250 bp were sequenced: a total of 171 clones for $S$. hirundinacea and 115 for $R$. niger. From these, 47 were microsatellite sequences in $S$. hirundinacea with only 13 in $R$. niger.

The cloning efficiency of our enriched libraries (percentage of positives clones obtained that contains microsatellite sequences from the total of recombinants) was $5.16 \%$ (in total for both species). This value is similar to those described in the literature for other bird species, such as the crested ibis Nipponia nippon (Ji et al., 2004; 4\%), but smaller when compared with other taxa, such as fish and mammals (Zane et al., 2002). Comparisons of these values are problematic due to the different isolation techniques used and their expected efficiency (see review in Zane et al., 2002 and Gregory and Quinn, 2006). Nevertheless, low values of cloning efficiency in enriched protocols have been attributed to the low number of microsatellites present in the taxon (as for example in lepidoptera, where cloning efficiency is around $2.5 \%$, Ji et al., 2003), which has led to several hypotheses about the origin of the reduced abundance of microsatellites in these genomes (Nève and Meglécz, 2000).

The non-enriched protocol yielded 466 recombinant clones for $S$. hirundinacea and 247 for $R$. niger. Here, only the positive clones for the PCR screening were sequenced (16 for S. hirundinacea and 8 for $R$. niger) and none of them were found to be true microsatellite sequences. The percentage of positive clones using traditional methods of microsatellite isolation (non-enriched libraries) has been found to be lower in birds $(0.46 \%)$, compared to other taxa, such as mammals (1.67\%) and fish (3.1\%; Primmer et al., 1997; Zane et al., 2002). Even considering that in our study a relatively low number of clones were screened (about 2000 ), our results suggested that the frequency of microsatellites in $S$. hirundinacea and $R$. niger may be than for other species of birds studied to date.

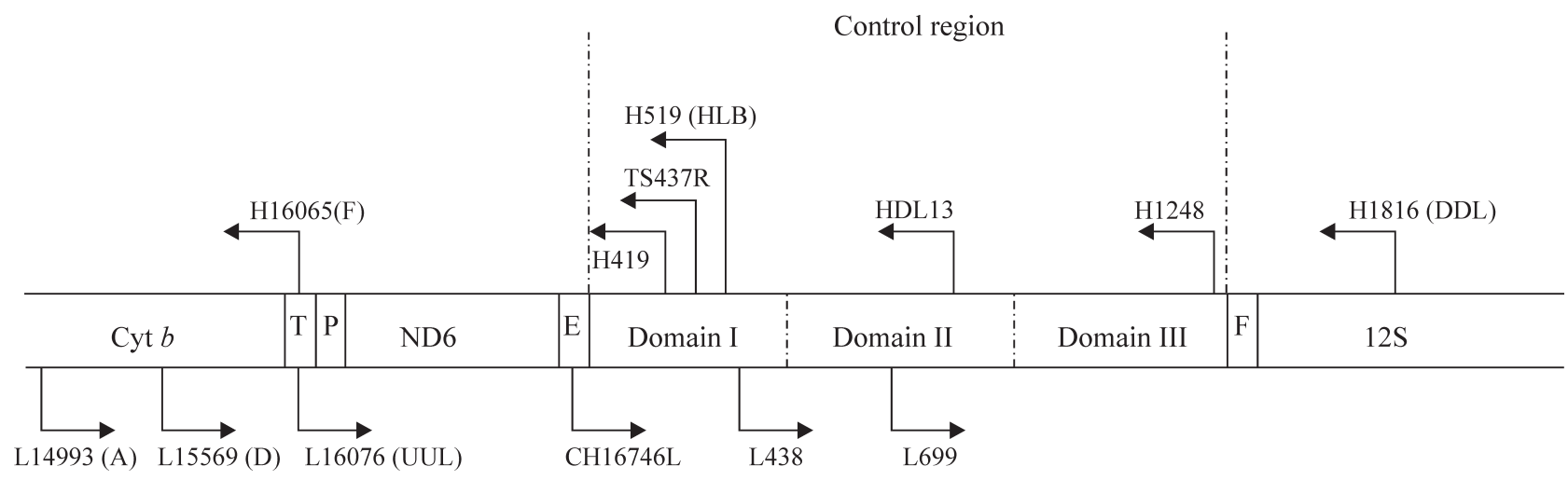

Figure 1 - Schematic diagram showing the locations of the primers used to amplify the mtDNA control region. 
Given et al. (2002) reported that for the development of polymorphic microsatellites for Larus novaehollandiae scopulinus, a gull species, it was necessary to carry out screening of 150,000 clones (using both procedures: enriched and non-enriched) of which only 39 contained microsatellites and seven were polymorphic. Until now, only four microsatellite loci have been isolated for the genus Sterna (Szczys et al., 2005). However, to obtain these markers, the authors reported that it was necessary to screen approximately 250 million base pairs of the Roseate tern (Sterna dougallii) genome, which produced 166 positive clones and only four polymorphic markers. In this study it was concluded that genomes in the genus Sterna are particularly poor in microsatellites (Szczys et al., 2005).

Our data could also be explained due to the low efficiency of the protocols used in this study or even by potential problems during the isolation of microsatellites. However, this seems unlikely for three main reasons. First, several studies using the same protocol (Hammond et al., 1998) have been successfully done (examples can be found in: Aransay et al., 2001; Bailey et al., 2005; Berendonk and Evans, 2004; Berendonk and Dobson, 2006; Burland et al., 2001; Horning et al., 2003; Liu et al., 2005; Liu et al., 2006; Pai et al., 2003; Tero and Schlotterer, 2005; Harper et al., 2006); Second, our laboratory is experienced in the development of microsatellites in different group of organisms, including birds (Jeffery et al., 2001), reptiles (Ciofi and Bruford, 1998); mammals (Radespiel et al., 2001), insects (Wilcock et al., 2001; Seabra et al., 2002; Williams et al., 2002) and earthworms (Harper et al., 2006); and third, the few reports on microsatellite isolation in this group of birds (only one record for Sterna; Szczys et al., 2005 and two for seagulls; Given et al., 2002; Tirard et al., 2002) and several personal communications from researchers that were not successful in the development of polymorphic loci in tern species.

From sixty positive clones containing true microsatellites obtained in our study (47 for S. hirundinacea and 13 for $R$. niger), using the enriched protocol, eighteen did not possess suitable flanking sequences for primer design, seven possessed very small number of repeat units $(<4)$ and twenty-seven were replicate sequences present in other clones. The libraries constructed in our study generated only eight primers pairs, six of which produced an amplification profile comprising a large number of bands, one of which presented a single product, but not of the expected size and one produced a monomorphic product in six different species of terns. Similar results of non-specific or repetitive DNA amplification have also been reported in lepidoptera. Recent studies of this group have shown the occurrence of microsatellite DNA families, with loci containing similar or almost identical flanking regions, that can complicate the selection of single locus markers (Nève and Meglécz, 2000; Zhang, 2004). These findings have been related to the genesis and spread of microsatellites in lepidop- tera (Nève and Meglécz, 2000; Zhang, 2004). It has been suggested that mobile elements could be involved in the evolutionary dynamics of microsatellites, including generation of the sequence followed by dispersal and diversification. Accordingly, in organisms that have low microsatellite frequencies and high redundancy, microsatellites would still be in the early stage of evolution and their flanking regions would not have accumulated many mutations (Ellegren, 2004; Zhang, 2004).

In conclusion, further effort is needed to isolate microsatellites specific for terns and skimmers before general conclusions can be drawn. However, it seems to date that the abundance of microsatellites in this group is lower than in other species and the level of redundancy is high. Further investigation into the evolutionary trajectory of microsatellites within this group is needed, as well as the development of new methods to increase the efficiency of microsatellite isolation.

Cross amplification of microsatellites. In birds, a wide survey of the literature has reported a success rate of cross amplification of $84 \%$ in several passerine species (Galbusera et al., 2000), while the level of polymorphism ranged from 39\% (Galbusera et al., 2000) to 46\% (Primmer et al., 1996). The probability of success seems to be higher in species that belong to the same genus or recently separated genera (Zane et al., 2002)

The results of the cross amplification in our data are shown in Table 1. Some loci did not amplify in some specimens in T. maximus (K67 and K16), S. hirundinacea (K67), S. fuscata (K16) and A. stolidus (Sdaat20) (Table 1). This result could be a consequence of the occurrence of null alleles in those species, therefore those primers were not used further.

The proportion of polymorphic markers in each species ranged from $16.6 \%$ in $A$. stolidus to $38 \%$ in S. fuscata (Table 2). These results are within the range obtained for other species of seabirds. In Rissa tridactyla, only $14.28 \%$ of the loci were polymorphic when used in Stercorarius parasiticus, a species belonging to a closely related family (Tirard et al., 2002). A recent survey of seventeen microsatellite loci developed for whiskered auklet (Aethia pygmaea) in 42 species of seabirds, showed that as the genetic distance increased, the level of polymorphism decreased more rapidly than amplification success (Dawson et al., 2005). The average level of polymorphism within the family was $52 \%$, while outside the family it dropped to $5 \%$ (Dawson et al., 2005). About $90 \%$ of the loci developed for Larus novaehollandiae scopulinus were polymorphic within the same genus (Given et al., 2002).

The use of primers developed for other species has thus proven to be a viable alternative, mainly when difficulties are associated with the isolation of specific markers. It is also useful when the study involves several related species and it is time-consuming and potentially inefficient to obtain specific markers for each one. 


\section{Mitochondrial DNA}

Considering the difficulties associated with the isolation of polymorphic microsatellite loci, it was decided to select mitochondrial DNA sequences that could also be highly informative for addressing questions concerning the population genetics of terns.

Control region. The most suitable region of the mtDNA for population studies is the control region (Dloop) because it evolves rapidly. This segment of the mtDNA has been used in several phylogeographic studies of seabirds (Kidd and Friesen, 1998; Burg and Croxall,
2001; Liebers et al., 2001; Abbot and Double, 2003). However, in some avian species, the control region is not more variable than coding genes (Randi and Lucchini, 1998; Crochet and Desmarais, 2000). In gulls, the third domain of the D-loop showed the same variation as the second domain and cytochrome $b$ gene. This slower rate of evolution could be partly explained by the existence of secondary structures in the third domain of the D-loop of these species (Crochet and Desmarais, 2000).

Sequences of the first domain of D-loop were used by Avise et al., (2000) in a phylogeographic study of the sooty tern (Sterna fuscata). For the amplification of this region,

Table 1 - Number of alleles found in each species of seabird for each primer combination. The number of individuals tested is shown in brackets.

\begin{tabular}{|c|c|c|c|c|c|c|c|}
\hline & $\mathrm{SH}$ & SF & SS & $\mathrm{TM}$ & PS & AS & $\mathrm{RN}$ \\
\hline K6 & $3(12)$ & $5(14)$ & $3(3)$ & $1(10)$ & $4(8)$ & $6(14)$ & $3(10)$ \\
\hline K16 & $4(12)$ & $2(2)^{*}$ & $2(4)$ & $2(10)$ & $1(8)$ & $1(14)$ & $3(10)$ \\
\hline K31 & NS & NS & NS & NS & NS & NS & NS \\
\hline $\mathrm{K} 32$ & $1(12)$ & $6(14)$ & $2(4)$ & $1(10)$ & $4(8)$ & $1(14)$ & $1(12)$ \\
\hline K56 & NS & NS & NS & NS & NS & NS & NS \\
\hline K67 & $2(8)^{*}$ & $2(14)$ & $2(4)$ & $1(6)^{*}$ & $2(8)$ & $1(14)$ & $1(12)$ \\
\hline K71 & NS & NS & NS & NS & NS & $1(14)$ & NS \\
\hline RBG13 & $2(17)$ & $6(14)$ & $2(2)$ & $1(10)$ & $3(8)$ & $1(14)$ & $1(11)$ \\
\hline RBG18 & $3(12)$ & $1(14)$ & $2(5)$ & $2(10)$ & $2(8)$ & $1(14)$ & $5(12)$ \\
\hline RBG20 & $1(12)$ & $2(14)$ & $3(4)$ & $2(8)^{*}$ & $1(8)$ & $2(75)$ & $1(11)$ \\
\hline RBG27 & $7(12)$ & $1(14)$ & $3(4)$ & $2(10)$ & $1(8)$ & $1(14)$ & $2(11)$ \\
\hline RBG28 & NS & NS & NS & NS & NS & $1(14)$ & $2(12)$ \\
\hline RBG29 & $4(12)$ & $8(14)$ & $1(5)$ & $1(10)$ & $2(8)$ & $1(14)$ & $1(12)$ \\
\hline RBG39 & NS & NS & NS & NS & NS & NS & NS \\
\hline Sdaat20 & $7(11)$ & $4(14)$ & $?$ & $1(10)$ & $4(8)$ & $2(7)^{*}$ & $4(5)$ \\
\hline Sdaat27 & $1(53)$ & $2(14)$ & $?$ & $2(10)$ & $1(8)$ & $2(15)$ & $2(11)$ \\
\hline Sdaat46 & - & - & - & - & - & - & - \\
\hline Scaac20 & $8(11)$ & $3(14)$ & $2(5)$ & $1(10)$ & $4(6)^{*}$ & $1(13)$ & $?$ \\
\hline
\end{tabular}

Abbreviations: SH (S. hirundinacea), TM (T. maximus), SF (S. fuscata), SS (S. superciliaris), PS (Phaetusa simplex), AS (Anous stolidus), and RN (Rynchops niger). NS = non-specific amplification; (-) non-amplification; *lack of amplification in some specimens; ? not tested.

Table 2 - Summary of the monomorphic and polymorphic microsatellite loci and its proportion in each species.

\begin{tabular}{|c|c|c|c|}
\hline Species & Monomorphic & Polymorphic & $\begin{array}{l}\text { Percentage of poly- } \\
\text { morphic markers }\end{array}$ \\
\hline S. hirundinacea & K32, K67, RBG13, RBG20, and Sdaat27 & $\begin{array}{l}\text { K6, K16, RBG18, RBG27, RBG29, Scaac20 } \\
\text { and Sdaat20 }\end{array}$ & 58.33 \\
\hline S. fuscata & K16, K67, RBG18, RBG20 and RBG27 & $\begin{array}{l}\text { K6, K32, RBG13, RBG29, Scaac20, Sdaat27 } \\
\text { and Sdaat20 }\end{array}$ & 58.33 \\
\hline S. superciliaris & $\begin{array}{l}\text { K16, K67, RBG13, RBG18, RBG28, RBG29 } \\
\text { and Scaac20 }\end{array}$ & K6, K32, RBG20 and RBG27 & 36.36 \\
\hline T. maximus & $\begin{array}{l}\text { K6, K16, K32, K67, RBG13, RBG29, Scaac20 } \\
\text { and Sdaat20 }\end{array}$ & RBG18, RBG27 and Sdaat27 & 27.27 \\
\hline P. simplex & $\begin{array}{l}\text { K16, RBG18, RBG20, RBG27, RBG29 and } \\
\text { Sdaat27 }\end{array}$ & K6, K32, K67, RBG13, Scaac20 and Sdaat20 & 50.00 \\
\hline Anous stolidus & $\begin{array}{l}\text { K16, K32, K67, K71, RBG13, RBG18, RBG20, } \\
\text { RBG27, RBG28, RBG29 and Scaac20 }\end{array}$ & K6, RBG20 and Sdaat27 & 21.42 \\
\hline Rynchops niger & K32, K67, RBG13, RBG20 and RBG29 & K6, K16, RBG18, RBG27, RBG28 and Sdaat20 & 54.54 \\
\hline
\end{tabular}


Table 3 - Number of haplotypes and values of nucleotide divergence in five species of terns and one species of black skimmer for each mtDNA gene sequences. The number of individuals tested is shown in brackets.

\begin{tabular}{lccc}
\hline Species & Cytochrome $b$ & ND2 & ATPase 6/8 \\
\hline S. hirundinacea & $2 / 0.006(21)$ & $2 / 0.002(17)$ & $2 / 0.002(11)$ \\
S. fuscata & $?$ & $3 / 0.006(16)$ & $3 / 0.006(13)$ \\
S. superciliaris & $1 / 0(4)$ & $?$ & $1 / 0(5)$ \\
T. maximus & $1 / 0(10)$ & $1 / 0(9)$ & $1 / 0(10)$ \\
P. simplex & $1 / 0(8)$ & $?$ & $?$ \\
Anous stolidus & $1 / 0(9)$ & $2 / 0.004(14)$ & $2 / 0.005(14)$ \\
Rynchops niger & $1 / 0(8)$ & $1 / 0(15)$ & $2 / 0.004(12)$ \\
\hline
\end{tabular}

?: not tested.

they used the primers CH1674 GL and T5437R, previously described for other species of birds (Wenink et al., 1994). In the present study, several trials were performed using this set of primers in the six species tested. For all species analyzed in our study, two fragments were obtained, sized $450 \mathrm{bp}$ (expected size) and $600 \mathrm{bp}$. Peck and Congdon (2004) also related difficulties associated to the use of these primers on the same species (Sterna fuscata) analyzed by Avise et al., (2000). After changes to the PCR conditions, a single fragment of $600 \mathrm{bp}$ was isolated. This fragment was sequenced and the resulting sequences were of good quality and without ambiguities. These sequences were submitted and aligned using BLASTn with those in the GenBank database (Accession number EF028082) and were matched to nuclear copies described for Cepphus (Alcidae) (Kidd and Friesen, 1998).

Avise et al. (2000), isolated mtDNA from tissues such as liver and muscle through $\mathrm{CsCl}$-ethidium bromide density gradient centrifugation. In the present study, only blood samples were used. Sorenson and Quinn (1998) pointed out that avian blood samples are particularly likely to yield Numts and should be avoided for mtDNA sequencing. Indeed, red blood cells in birds are nucleated and relatively depauperate in mtDNA. Instead of total genomic extractions, the use of purified mtDNA from mtDNA-rich tissues is preferred.

The occurrence of Numts can be detected when: 1) the PCR amplification produces more than one band; 2) there are ambiguities in the sequence or poor quality; 3 ) there are stop codons, frameshifts, deletions or insertions in gene sequences; and 4) when the analysis produces contradictory results (Zhang and Hewitt, 1996). Unfortunately, it is not always possible to identify Numts at the first three steps (as happened in our study) and sometimes the detection occurs when all the laborious work has been done and misleading results have been reported as a consequence including in Genbank (Clifford et al., 2004; Anthony et al., 2007).

Identification of nuclear copies of mtDNA is important because unrecognized inclusion of Numts in an analysis can lead to incorrect conclusions and can invalidate the analyses. However, nuclear integrations provide a real opportunity to study the relative rate of evolution of nuclear and mitochondrial sequences and in calibration of sequence divergence (Zhang and Hewitt, 1996; Sorenson and Quinn, 1998; Bensasson et al., 2001).

Other experiments were carried out in an attempt to sequence the second and third domain of D-loop and the whole control region using the primer sets described in $\mathrm{Ma}$ terial and Methods. Long PCR was also used in order to avoid nuclear copies and identify the true mtDNA sequence. Non-specific fragments were produced on amplification of the second and third domain and the whole control region.

Mitochondrial genes. Considering the problems related to sequencing of the control region, it was decided to evaluate the utility of mitochondrial genes in this study. Cytochrome $b$, ND2 and ATPase 6/8 were chosen as candidates. Cytochrome $b$ is one of the most commonly utilized mtDNA genes in phylogenetics, however, it does not always seem to be the optimal choice. According to Sorenson (2003), all mitochondrial protein genes have similar rates of substitution at the third codon position, but vary in the rate of amino acid substitution. Certain proteins, such as the Cytochrome $b$ are subject to more biochemical constraints than others and, as a result, the levels of homoplasy are often higher than in comparatively unconstrained regions (Johnson and Sorenson, 1998).

In terms of variation, ATPase 8, ND6 and ND2 are considered the most variable genes in birds. However, due to the small size of ATPase 8 and the unusual base composition and location of ND6, they often provide little information (Sorenson, 2003). Sequences of ND2 and ATPase $6 / 8$ have been used in several phylogenetic and phylogeographic studies (Garcia-Moreno et al., 2004; Kennedy and Spencer, 2004; Overton and Rhoads, 2004; Given et al., 2005; Zink, 2005).

Partial sequences of cyt $b$, ND2 and ATPase 6/8 genes were obtained for each of the six species studied $(S$. hirundinacea, $S$. fuscata, $S$. superciliaris, $T$. maximus, $P$. simplex and $R$. niger). The values of nucleotide divergence ranged from 0.0 to 0.006 within species (Table 3 ). Consequently, their usefulness for genetic studies is limited and depends on the species analyzed and the questions addressed. Unfortunately, it is impossible to know in advance which gene will be informative in which species for conducting studies at population level.

It seems that the selection of suitable (variable) molecular markers to address questions of population and evolutionary genetics for terns is not a straightforward task and significant effort is needed for each species. However, despite all difficulties encountered during the course of this study, polymorphic markers were selected for each species and can potentially be used in further genetic studies of this group of seabirds. Reports on potential problems encountered during the selection of molecular markers are also im- 
portant to improve general understanding of their dynamics in different groups.

For future studies involving population genetics of terns, the utilization of other kinds of molecular markers that have proved to be suitable to conduct genetic studies in other species of birds might be considered, such as nuclear introns (Congdon et al., 2000; Pacheco et al., 2002; Friesen et al., 2005; Whittier et al., 2006), SNPs (Saetre et al., 2001; Bensch et al., 2002) and AFLP (Wang et al., 2003; Boulet et al., 2005; Helbig et al., 2005).

In a recent study, cytochrome $b$ and nuclear introns (332pb of $\alpha$-enolase and 289 bp of glyceraldehydes-3phosphate dehydrogenase) were used to determine the genetic variation among subspecies of Least tern. Low genetic variability was found using all markers: only three cyt $b$ haplotypes in 50 individuals, a single allele using Enol and three alleles using Gadp (Whittier et al., 2006). Our findings in addition to the published record suggest that this group of birds presents low levels genetic variation despite the choice of the molecular markers. Further studies need to be done in order to confirm these results, nevertheless if they prove to be general the causes and consequences of this lack of genetic variation needs to be further investigated.

\section{Acknowledgements}

We thank Fausto P. Campos, Sérgio L. Pereira, Sílvia R. Blanco, Simon P. Shayler, Sofia Seabra and Trinidad Pérez for suggestions and support in lab work. Patricia Szczys for provided Roseate tern microsatellites primers before their publication. Kate Devlin, Ann Lashko, Gernot Segelbacher, Veronica Neves and Dorit Liebers for sharing information about genetics of seabirds. This research was funded by Cardiff University, Wales, UK and Fundação de Amparo à Pesquisa do Estado de São Paulo (FAPESP, Process n. 01/01868-7 and 00/13213-2). Blood samples were taken under IBAMA permissions (228/2001, 008/2002, 022/2003, 033/2004; DEUCs: 039/2004, 060/2003, $136 / 2001$ and $057 / 2001$ ).

\section{References}

Abbott CL and Double MC (2003) Genetic structure, conservation genetics and evidence of speciation by range expansion in shy and white-capped albatrosses. Mol Ecol 12:29532962.

Anthony NM, Clifford SL, Bawe-Johnson M, Abernethy KA, Bruford MW and Wickings EJ (2007) Distinguishing gorilla mitochondrial sequences from nuclear integrations and PCR recombinants: Guidelines for their diagnosis in complex sequence databases. Mol Phylogenet Evol 43:553-566.

Aransay AM, Malarky G and Ready PD (2001) Isolation (with enrichment) and characterization of trinucleotide microsatellites from Phlebotomus perniciosus, a vector of Leishmania infantum. Mol Ecol Notes 1:176-178.
Arctander P (1995) Comparison of a mitochondrial gene and a corresponding nuclear pseudogene. Proc Royal Soc Lond B 262:13-19.

Avise JC, Nelson WS, Bowen BW and Walker D (2000) Phylogeography of colonially nesting seabirds with special reference to global matrilineal patterns in the sooty tern (Sterna fuscata). Mol Ecol 9:1783-1792.

Bailey NW, Hockham LR, Graves JA and Ritchie MG (2005) Development and characterization of microsatellite loci in Mormon crickets (Anabrus simplex, Orthoptera, Tettigoniidae). Mol Ecol Notes 5:613-615.

Beaumont MA and Bruford MW (1999) Microsatellites in conservation genetics. In: Goldstein DB and Schlotterer C (eds) Microsatellites: Evolution and Application. Oxford University Press, Oxford, pp 165-182.

Bensasson D, Zhang DX, Hartl DL and Hewitt GM (2001) Mitochondrial pseudogenes: Evolution's misplaced witnesses. Trends Ecol Evol 16:314-321.

Bensch S, Akesson S and Irwin DE (2002) The use of AFLP to find an informative SNP: Genetic differences across a migratory divide in willow warblers. Mol Ecol 11:2359-2366.

Berendonk TU and Evans T (2004) Isolation of polymorphic microsatellite loci in three phantom midge species of the genus Chaoborus (Diptera, Chaoboridae). Mol Ecol Notes 4:250-252.

Berendonk TU and Dobson K (2006) Isolation of polymorphic microsatellite loci in the clear lake gnat and two other phantom midge species of the genus Chaoborus (Diptera, Chaoboridae). Mol Ecol Notes 6:17-19.

Boulet M, Potvin C, Shaffer F, Breault A and Bernatchez L (2005) Conservation genetics of the threatened horned grebe (Podiceps auritus L.) population of the Magdalen Islands, Québec. Conserv Genet 6:539-550.

Bruford MW, Cheesman DJ, Coote T, Green HAA, Haines SA, O'Ryan C and Williams TR (1996) Microsatellites and their application to conservation genetics. In: Smith TB and Wayne RK (eds) Molecular Genetic Approaches in Conservation. Oxford University Press, New York, pp 278-297.

Burg TM and Croxall JP (2001) Global relationships amongst black-browed and grey-headed albatrosses: Analysis of population structure using mitochondrial DNA and microsatellites. Mol Ecol 10:2647-2660.

Burland TM, Bishop JM, O'Ryan C and Faulkles CG (2001) Microsatellite primers for the African mole-rat genus Cryptomys and cross-species amplification within the family Bathyergidae. Mol Ecol Notes 1:311-314.

Ciofi C and Bruford MW (1998) Isolation and characterization of microsatellite loci in the Komodo dragon Varanus komodoensis. Mol Ecol 7:134-136.

Clifford SL, Anthony NM, Johnson-Bawe M, Abernethy KA, Tutin CEG, White LJT, Bermejo M, Goldsmith ML, McFarland K, Jeffery KJ, et al. (2004) Mitochondrial DNA phylogeography of western lowland gorillas (Gorilla gorilla gorilla). Mol Ecol 13:1551-1565.

Crochet PA and Desmarais E (2000) Slow rate of evolution in the mitochondrial control region of gulls (Aves, Laridae). Mol Biol Evol 17:1797-1800.

Congdon BC, Piatt JF, Martim K and Friesen VL (2000) Mechanisms of population differentiation in marbled murrelets: Historical versus contemporary processes. Evolution 54:974-986. 
Dawson DA, Hunter FM, Pandhal J, Buckland R, Parham A, Jones IL, Bradshaw M, Jehle R and Burke T (2005) Assessment of 17 new whiskered auklet (Aethia pygmaea) microsatellite loci in 42 seabirds identifies 5-15 polymorphic markers for each of nine Alcinae species. Mol Ecol Notes 5:289-297.

Desjardin P and Morais R (1990) Sequence and gene organization of the chicken mitochondrial genome: A novel gene order in higher vertebrates. J Mol Biol 212:599-634.

Ellegren H (2004) Microsatellites: Simple sequences with complex evolution. Nat Rev Genet 5:435-445.

Friesen VL, Birt TP, Piatt JF, Golightly RT, Newman SH, Hébert PN, Congdon BC and Gissing G (2005) Population genetic structure and conservation of marbled murrelets (Brachyramphus marmoratus). Conserv Genet 6:607-614.

Galbusera P, Dongen SV and Mattysen E (2000) Cross-species amplification of microsatellite primers in passerine birds. Conserv Genet 1:163-168.

García-Moreno J, Navarro-Siguenza AG, Peterson AT and Sánchez-González LA (2004) Genetic variation coincides with geographic structure in the common bush-tanager (Chlorospingus ophthalmicus) complex from Mexico. Mol Phylogenet Evol 33:186-196.

Given AD, Mills A and Baker AJ (2002) Isolation of polymorphic microsatellite loci from the red-billed gull (Larus novaehollandiae scopulinus) and amplification in related species. Mol Ecol Notes 2:416-418.

Given AD, Mills JA and Baker AJ (2005) Molecular evidence for recent radiation in southern hemisphere masked gulls. Auk 122:268-279.

Gochfeld M and Burger J (1996) Family Sternidae (terns). In: Del Hoyo J, Elliot A and Sargatal J (eds) Handbook of the Birds of the World. v. 3. Lynx Edicion, Barcelona, pp 572-623.

Gregory SM and Quinn JS (2006) Microsatellite isolation from four avian species comparing two isolation techniques. Mol Ecol Notes 6:87-89.

Hammond RL, Saccheri IJ, Ciofi C, Coote T, Funk SM, McMillan O, Bayes MK, Taylor E and Bruford MW (1998) Isolation of microsatellite markers in animals. In: Karp A, Isaac PG and Ingram DS (eds) Molecular Tools for Screening Biodiversity. Chapman \& Hall, London, pp 279-287.

Harper GL, Cesarini S, Casey SP, Morgan AJ, Kille P and Bruford MW (2006) Microsatellite markers for the Earthworm Lumbricus rubellus. Mol Ecol Notes 6:325-327.

Helbig AJ and Seibold I (1999) Molecular phylogeny of paleartic-african Acrocephalus and Hippolais warblers (Aves, Sylviidae). Mol Phylogenet Evol 11:246-260.

Helbig AJ, Seibold I, Kocum A, Liebers D, Irwin J, Bergmanis U, Meyburg Bu, Scheller W, Stubbe M and Bensch S (2005) Genetic differentiation and hybridization between greater and lesser spotted eagles (Accipitriformes, Aquila clanga, A. pomarina). J Ornithol 146:226-234.

Horning ME, Maloney SC and Webster MS (2003) Isolation and characterization of variable microsatellite loci in Lilium philadelphicum (Liliaceae). Mol Ecol Notes 3:412-413.

Jeffery KJ, Keller LF, Arcese P and Bruford MW (2001) The development of microsatellite loci in the song sparrow, Melospiza melodia (Aves) and genotyping errors associated with good quality DNA. Mol Ecol Notes 1:11-13.

Ji YJ, Zhang DX, Hewitt GM, Kang L and Li DM (2003) Polymorphic microsatellite loci for the cotton bollworm
Helicoverpa armigera (Lepidoptera, Noctuidae) and some remarks on their isolation. Mol Ecol Notes 3:102-104.

Ji YJ, Liu YD, Ding CQ and Zhang DX (2004) Eight polymorphic microsatellite loci for the critically endangered crested ibis, Nipponia nippon (Ciconiiformes, Threskiornithidae). Mol Ecol Notes 4:615-617.

Johnson KJ and Sorenson MD (1998) Comparing molecular evolution in two mitochondrial protein coding genes (cytochrome $b$ and ND2) in the dabbling ducks (Tribe, Anatini). Mol Phylogenet Evol 10:82-94.

Kennedy M and Spencer HG (2004) Phylogenies of the frigatebirds (Fregatidae) and tropicbirds (Phaethonidae), two divergent groups of the traditional order Pelecaniformes, inferred from mitochondrial DNA sequences. Mol Phylogenet Evol 31:31-38.

Kidd MG and Friesen VL (1998) Analysis of mechanisms of microevolutionary change in Cepphus guillemots using patterns of control region variation. Evolution 52:1158-1168.

Kocher TD, Thomas WK, Meyer A, Edwards SV, Pääbo S and Villablanca FX (1989) Dynamics of mitochondrial DNA evolution in animals: Amplification and sequencing with conserved primers. Proc Natl Acad Sci USA 86:6196-6200.

Liebers D, Helbig AJ and Knijff P (2001) Genetic differentiation and phylogeography of gulls in the Larus cachinnans-fuscus group (Aves, Charadriiformes). Mol Ecol 10:2447-2462.

Liu Z, Zhang B, Wei F and Li M (2005) Isolation and characterization of microsatellite loci in the red panda, Ailurus fulgens. Mol Ecol Notes 5:27-29.

Liu YD, WU KM and Guo YY (2006) Isolation and characterization of polymorphic microsatellite loci from the pink bollworm Pectinophora gossypiella (Saunders) (Lepidoptera, Gelechiidae). Mol Ecol Notes 6:847-849.

Lopez JV, Yuhki N, Masuda R, Modi W and O'Brien SJ (1994) Numt, a recent transfer and tandem amplification of mitochondrial DNA to the nuclear genome of the domestic cat. J Mol Evol 39:174-190.

Lunt DH, Hutchinson WF and Carvalho GR (1999) An efficient method for PCR-based isolation of microsatellite arrays (PIMA). Mol Ecol 8:891-994.

Overton LC and Rhoads DD (2004) Molecular phylogenetic relationships based on mitochondrial and nuclear gene sequences for the todies (Todus, Todidae) of the Caribbean. Mol Phylogenet Evol 32:524-538.

Mourier T, Hansen AJ, Willerslev E and Arctander P (2001) The human genome project reveals a continuous transfer of large mitochondrial fragments to the nucleus. Mol Biol Evol 18:1833-1837.

Neff BD and Gross MR (2001) Microsatellite evolution in vertebrates: Inference from AC dinucleotide repeats. Evolution 55:1717-1733.

Nève G and Meglécz E (2000) Microsatellite frequencies in different taxa. Trends Ecol Evol 15:376-377.

Pacheco NM, Congdon BC and Friesen VL (2002) The utility of nuclear introns for investigating hybridization and genetic introgression: A case study involving Brachyramphus murrelets. Conserv Genet 3:175-182.

Pai A, Sharakhov IV, Braginets O, Costa C and Yan G (2003) Identification of microsatellite markers in the red flour beetle, Tribolium castaneum. Mol Ecol Notes 3:425-427. 
Peck DR and Congdon BC (2004). Reconciling historical processes and population structure in the sooty tern Sterna fuscata. J Avian Biol 35:327-335.

Primmer CR, Moller AP and Ellegren H (1996) A wide range survey of cross species microsatellite amplifications in birds. Mol Ecol 5:365-378.

Primmer CR, Raudsepp T, Chowdhary BP, Moller AP and Ellegren H (1997) Low frequency of microsatellites in the avian genome. Genome Res 7:471-482.

Quinn TW (1992) The genetic legacy of Mother Goose - Phylogeographic patterns of Lesses Snow Goose Chen caerulescens maternal lineages. Mol Ecol 1:105-117.

Radespiel U, Funk SM, Zimmermann E and Bruford MW (2001) Isolation and characterization of microsatellite loci in the grey mouse lemur (Microcebus murinus) and their amplification in the family Cheirogaleidae. Mol Ecol Notes 1:1618.

Randi E and Lucchini V (1998) Organization and evolution of the mitochondrial DNA control region in the avian genus Alectoris. J Mol Evol 47:449-462.

Richly E and Leister D (2004) NUMTs in sequenced eukaryotic genomes. Mol Bio Evol 21:1081-1084.

Saccheri IJ and Bruford MW (1993) DNA fingerprinting in a butterfly Bicyclus anynana (Satyridae). J Hered 84:195-200.

Saetre GP, Borge T, Lindell J, Moum T, Primmer CR, Sheldon BC, Haavie J, Johnsen A and Ellegren H (2001) Speciation, introgressive hybridization and nonlinear rate of molecular evolution in flycatchers. Mol Ecol 10:737-749.

Sambrook J, Fritsch E and Maniatis T (1989) Molecular Cloning: A Laboratory Manual. Cold Spring Harbor Press, New York.

Seabra, SG, Wilcock, HR, Quartau, JA and Bruford MW (2002) Microsatellite loci from the Mediterranean species Cicada barbera (Stal) and C. orni L. (Hemiptera, Cicacoidea). Mol Ecol Notes 2:173-175.

Sorenson MD (2003) Avian mtDNA primers. Boston University. Available at: http://people.bu.edu/msoren/primers.html.

Sorenson MD, Ast JC, Dimcheff DE, Yuri T and Mindell DP (1999) Primers for a PCR based approach to mitochondrial genome sequencing in birds and other vertebrates. Mol Phylogenet Evol 12:105-114.

Sorenson MD and Quinn TW (1998) Numts: A challenge for avian systematics and population biology. Auk 115:214221.

Squirrell J, Hollingsworth PM, Woodhead M, Russell J, Lowe AJ, Gibby M and Powell W (2003) How much effort is required to isolate nuclear microsatellites from plants? Mol Ecol 12:1339-1348.

Szczys P, Hughes CR and Kesseli RV (2005) Novel microsatellite markers used to determine the population genetic structure of the endangered Roseate Tern, Sterna dougallii, in Northwest Atlantic and Western Australia. Conserv Genet 6:461466.

Tero N and Schlötterer C (2005) Isolation and characterization of microsatellite loci from Silene tatarica. Mol Ecol Notes 5:517-518.

Thalmann O, Serre D, Hofreiter M, Lukas D, Eriksson J and Vigilant L (2005) Nuclear insertions help and hinder inference of the evolutionary history of gorilla mtDNA. Mol Ecol 14:179-188.

Tirard C, Helfenstein F and Danchin E (2002) Polymorphic microsatellites in the black-legged kittiwake Rissa tridactyla. Mol Ecol Notes 2:431-433.

Tourmen Y, Baris O, Dessen P, Jacques C, Malthiery Y and Reynier P (2002) Structure and chromosomal distribution of human mitochondrial pseudogenes. Genomics 80:71-77.

Wang Z, Baker AJ, Hill GE and Edward SV (2003) Reconciling actual and inferred populations histories in the house finch (Carpodacus mexicanus) by AFLP analysis. Evolution 57:2852-2864.

Wenink PW, Baker AJ and Tilanus MGJ (1993) Hypervariablecontrol-region sequences reveal global population structuring in a long distance migrant shorebird, the dunlin (Calidris alpina). Proc Natl Acad Sci USA 90:94-98.

Wenink PW, Baker AJ and Tilanus MGJ (1994) Mitochondrial control-region sequences in two shorebird species, the turnstone and the dunlin, and their utility in population genetic studies. Mol Biol Evol 11:22-31.

Whittier JB, Leslie DM and Van den Bussche RA (2006) Genetic variation among subspecies of Least tern (Sterna antillarum): Implications for conservation. Waterbirds 29:176-184.

Wilcock HR, Hildrew AG, Nichols RA and Bruford MW (2001) Isolation and characterisation of microsatellites in the caddis fly Plectrocnemia conspersa. Mol Ecol Notes 1:318-320.

Williams HC, Wilcock HR and Bruford MW (2002) Microsatellite loci for the mayfly Baetis rhodani (Baetidae, Ephemeroptera). Mol Ecol Notes 2:411-412.

Zane L, Bargelloni L and Patarnello T (2002) Strategies for microsatellite isolation: A review. Mol Ecol 11:1-16.

Zhang D (2004) Lepidopteran microsatellite DNA: Redundant but promising. Trends Ecol Evol 19:507-509.

Zhang D and Hewitt GM (1996) Nuclear integrations: Challenges for mitochondrial DNA markers. Trends Ecol Evol 11:247251.

Zink RM (2005) Natural selection on mitochondrial DNA in Parus and its relevance for phylogeographic studies. Proc Royal Soc Lond B 272:71-78.

Associate Editor: Fábio de Melo Sene 